\title{
MAN.16 - The management of Brazilian genetic resources in a public translational research center in accordance with the new legal framework
}

\author{
Fabricia Pires Pimenta ${ }^{1 \star}$; Poliana Belisário Zorzal ${ }^{1}$. \\ 1Fiocruz/CDTS.
}

Introduction: The biodiversity has been used as a model for generation of solutions to the society. And the knowledge about natural products and processes has been used as a support for many product developments or in relevant scientific researches. Since the publication of Provisional Act 2,186-16 / 2001 (PA), in force since 2000, the protection of Brazilian genetic resources (GR) and associated traditional knowledge (TK) is the subject of a rather controversial debate. This scenario was restrained by the new legal framework, in force since 2015, and better understood by the decree publication in 2016. Due to the new rules and requirements, the institutions must to be regularized in face of the legal uses of Brazilian GR and TK.

Objective: The present study aimed to provide a guide to perform the management of GR and TK in a public institution. The guide could be used for regularization purposes and also for monitoring future uses in scientific and development projects, in order to advise researchers to be according to law requirements.

Methodology: The management was conducted in two lines of action. In one hand, initiatives of literacy about the topic were carrried out, by collective and personal approaches. In parallel, the Lattes curriculum and the institutional repository of all researchers and students associated to the Research Center were analyzed. After this mapping, the scientific and technological production was analyzed in order to identify the PG's uses and the necessary actions to be done. These analyses were consolidated in an official document and communicated personally to the researcher. After mapping and communication, monitoring actions will be done in order to mitigate or prevent deviation from legal requirements.

Results: 19 Official reports identified ten principal investigators that have to regularize published actions of PG accesses in the SisGen electronic system. Many meetings with researchers occurred until the whole information was evaluated concerning the legal requirements and exceptions. 10 registrations were done due to regularization process, 2 registrations due to monitoring actions in a one year period.

Conclusion: Public institutions have been done many efforts to achieve requirements of the new biodiversity legal frameworks. Management strategies, such as personal approaches and scientific and technological mapping were carried out to attain regularization of projects of a Public Translational Research Center. These actions permitted to better manage problems, avoid law misinterpretations and protect research development.

Keywords: Brazilian genetic patrimony; project management; biodiversity 